\title{
Becoming roller derby grrrls: Exploring the gendered play of affect in mediated sport cultures
}

\begin{abstract}
This article explores how the global revival of roller derby as an alternative sport for women has been mobilised through on-line social networks, league promotion and fan sites that create imagined communities of 'roller grrrls'. In the creation of sport culture we argue that the virtual performance of 'derby' identities is as significant as the embodiment of play. Like other sports derby sites mobilise affect (passion, pleasure, pain, desire to play) through a discourse of 'empowerment' that urges women to overcome limits and reinvent gendered subjectivity. However, within the virtual space of roller derby complex affects are produced and circulated within power relations that can include or exclude. Through an analysis of the way affect is mobilized in selected roller derby sites we identify how virtual sport identities are connected through the movement of 'affects' across bodies and leagues. These affects both circumscribe and undermine the notion of a single derby community.
\end{abstract}

Keywords: sport, gender, affect, virtual, embodiment 


\section{Introduction:}

TV is for old school derby. Twitter, RSS, Live Blogging, streaming video are the best way to feel close to the action when you can't afford to make that trip across country for a tournament!(2008)

As this opening quotation attests, roller derby is a sport that has been reinvented in the contemporary era of new digital technologies. This 'digital' context has profoundly shaped its cultural forms of play, spectating and fandom in a global context. Roller derby was a popular sport spectacle in the 1960s and 1970s with paid professional skaters, faux violence, television coverage and a tough image. The first incarnation of the game occurred in the late 1920s and since then has been re-invented several times, with its latest re-emergence quickly gaining momentum across the globe (Mabe, 2008). In 2001 a group of women in the US reclaimed the sport, creating a different emphasis, different rules, a flat track and overt connections with third wave feminist groups such as the Riot Grrrl ${ }^{1}$ (Pavlidis, 2011; Storms, 2010). The roller derby of the past was played by men and women equally (Mabe, 2008), although women were always paid less (Storms, 2010). The 'new' version was, initially, exclusively played and organised by women with a strong focus on DIY (Do it Yourself) (Beaver, 2012), music subcultures (Pavlidis, 2011) and alternative feminine identities (Finley, 2010). Roller derby refined itself as both a sport and as an empowering space for women to express alternative identities.

Roller derby's growing popularity - as evidenced by the number of leagues being established and the number of names being registered with the international names register ${ }^{2}$ - highlights the need for further understanding of the dynamics of this complex 'new' sport. In a very short time, between the 'revival' of roller derby in 2001 and in 2012 when this article was written, there were over 34,735 active skaters 
recorded internationally (n.d.). The growing popularity of roller derby raises critical questions about the cultural forces that shape women's desire to engage in a sport that defines itself as alternative and empowering through its challenge to normative gender ideals.

Roller derby communities consist of local and globalised networks of players, coaches, referees, officials and fans. The use of digital communication technologies, although by no means unique to roller derby, has opened up a space for creative articulations of the sport through 'cultural artefacts' such as, poetry, blogs, short stories, film and art, that evoke the corporeality of sport (see also Booth, 2008: on surfing magazines as cultural artefacts). The growth of this creative, virtual aspect of derby culture engages the desires of different women and opens up a discursive space for the play of gender identities. The popularity of roller derby presents an opportunity to better understand the nexus between creativity and sport which may provide insights into how to counter the persistent gender inequities in women's sport and leisure participation (Australian Bureau of Statistics, 2006; Hargreaves, 1990; Wearing, 1998).

Over the past 10 years there has been a proliferation of websites dedicated to supporting, producing and circulating roller derby identities that are both individual and collective. This visual and textual realm of derby culture also includes a range of cultural artifacts such as clothing and music, as well as a range of sport specific rules and official documents. The roller derby phenomenon is aptly described by Urry in relation to the 'increased mediatization of social life as images circulate increasingly fast and with added reach so as to form and reform various imagined communities' (2007: 9). Derby has become a sport where the boundary between the 'real' and the 'virtual' is inevitably blurred. 
Primarily a women's sport $^{3}$ (Donnelly, 2012), derby presents an opportunity for women to position themselves as intelligible subjects, capable of complex and at times dangerous improvisation (Pavlidis, 2011). Derby privileges the affective, sensual aspects of sport, allowing women to create a space of desire for themselves that is also culturally situated (see Wearing, 1998). In the popular literature, the sport is explicitly connected to particular affects and emotions. Joulwan (2007), who was part of the initial roller derby revival in the United States, goes so far as to outline her 'derby playlist', stating 'it's a mix of songs that I associate with being powerful, aggressive and sexy - the emotions I try to channel when I hit the track' (Joulwan, 2007: 153). Despite this comment by Joulwan, the complex affective relationships played out in virtual and embodied spaces have yet to be explored within the literature on roller derby. In this article we examine the role of new media in the production (and regulation) of affective experiences of roller derby as a virtual space for women's sporting desire. Like Elspeth Probyn we explore the dynamics of movement and embodied meaning: 'Desire here is not a metaphor; it is a method of doing things, of getting places... of connection and communication between things' (Probyn, 1996: 41). Skating is for many women, like riding was for Probyn, a 'wild passion', one that is 'addictive for speed, the motion, the feeling of and the desire for being at the very edge of control' (Probyn, 1996: 39). The desire for being on the edge of control is the desire for affect; to be affected and to affect others within a sport community.

\section{Roller derby and the play of gender identity}

Roller derby, as an embodied cultural practice, is one marked by speed and movement. The sport is played hard and fast, thus requiring both strength and fitness. With cultural references to rock ' $n$ ' wrestling, pin up girls, comic book heroines and 
dominatrix, roller derby evokes multiple meanings that invite diverse forms of identification and desiring femininities. The emerging literature on roller derby draws on feminist perspectives to argue that sport is a site for reinforcing and undermining gender inequality. Sport can provide women with experiences that 'empower', 'heal', and 'transform' them as individuals and more broadly challenge cultural norms about women's embodied capacities. Much of the feminist analysis of roller derby communities struggles to overcome an apparent impasse about whether the sport is empowering for women. Derby tends to be viewed as a cultural site that reinscribes a sexualized hyperfemininity while unproblematically adopting masculine aggressiveness. For Carlson $(2010 ; 2011)$, roller derby presents an opportunity for participants to undermine norms regarding feminine fragility and traditional female gender norms. However, despite this assertion Carlson noticed the 'stigmatization of certain feminine stereotypes' (2010: 436) within the league she was involved with. What Carlson identified was the rejection of 'girls being girls' and the embrace of a different sense of women's athleticism.

In another American study, Finley (2010) highlights how, in their gender maneuvering, skaters transport content from other experiences, life histories, and structural domains that are usually stigmatized, and employ it to femininize their activities. Where they may have been considered pariahs in other settings, in roller derby, these non-conforming attributes become the honored. Yet Finley (2010) also finds that the privileging of pariah identities leaves out the possibility of multiple ways of being or becoming a 'derby girl'. More recently Donnelly's (2012) doctoral research explored the complexities inherent in 'women only' spaces such as roller derby and home improvement workshops. Despite the recent academic interest in roller derby as a women's sport there has been little analysis of the dynamics of affect 
or emotion in the range of contemporary approaches (Carlson, 2010; Cohen, 2008; Donnelly, 2012; Finley, 2010; Kearney, 2011; Pavlidis, 2011; Peluso, 2011; Storms, 2010).

In this article we contribute a different focus on the affective dimension of roller derby and the way in which women constantly negotiate gender contradictions as they put their bodies on the line and identities in play through the virtual spaces of sport. In this sense, we move beyond a polemic reading of roller derby where feminine subjects are produced as either 'good or bad', 'hyper or normal'. Instead, we ask how does roller derby 'move' and affect women through the play of identity in virtual spaces and representations? Taking inspiration from the privileging of movement and affect in sociology and cultural studies knowledge we analyze how mediated cultures of roller derby enable women to 'exist beyond their private bodies, leaving traces of their selves in space' (Urry 2007: 15).

\section{New media, sport and affect}

There has been a plethora of research into the everyday cultural meanings, practices and deployment of digital technologies that have accompanied the growth of the Internet. Since the early 1990s researchers working in the areas of sport (MacKay and Dallaire, 2012; Ruddock, Hutchins and Rowe, 2010; Wilson, 2008), feminism (Driscoll, 1999; Luckman, 1999), media, and subcultures (Gibson, 1999; Hodkinson, 2003; Kahn and Kellner, 2003; Kahn and Kellner, 2004; Williams, 2003) have brought 'virtual' spaces and representations to the fore of their work. Initially a site for 'consumption', the Internet now enables users to produce as well as consume text, ideas, images, sounds, and narratives (Castells, 2003; Manovich, 2009). In particular, research examining riot grrrls (Garrison, 2000) and cybergirls (Driscoll, 1999) 
highlights how the Internet has been used by women to produce alternative femininities that circulate within a globalised geography.

In the more specific area of sport sociology research has begun to examine how the Internet figures within individual and collective identity formation, and most of this research utilizes a [post]subcultural studies framework (Wilson, 2008). Leonard writes, 'sports studies continues to lag behind in terms of analysis and critical interrogation of new media' (2009: 2). This 'lag' is being addressed on several fronts, including examinations of 'traditional' masculine sports (Dart, 2009; Oates, 2009), 'lifestyle'/'subcultural' sports (Wilson, 2008) and, more recently, (re)presentations of gender and sport online (MacKay and Dallaire, 2012). Women in sport are given dramatically less coverage within mainstream media as compared to men $(7 \%$ compared to 86\%) (Lumby, Caple and Greenwood, 2009). For this reason the proliferation and accessibility of blogs, social network sites and user-produced content has been vital for the promotion and celebration of women and sport as well as the opportunity for women to challenge and rewrite gender and sport identities. Niche media, as opposed to mass media (Thorpe, 2008), and zines, such as those produced and circulated by members of the Riot Grrrl scene (Harris, 2003), have also been a site for the production of alternative femininities.

A recent example of the way women are using the Internet in sport is explored in an article by MacKay and Dallaire (2012) who examine a blog produced by the 'Skirtboarders', a female skateboard crew based in Canada. The authors view gender as performative and examine how women (re)present themselves online via images and text. In the 'Skirtboarders' blog MacKay and Dallaire found multiple narratives of femininities being presented, including 'stereotypical femininity' (2012: 15). Our analysis departs from MacKay and Dallaire's account and previous work on sport and 
the web, drawing from a different theoretical tradition focused on affect. Like Booth's (2008) analysis of affect within the popular surfing magazine, Tracks, we consider the capacity of images and text to 'move' the reader in particular ways. Drawing from the work of Gibbs (2001) and Gregg (2006), Booth writes of the way the mass media amplifies, heightens and intensifies affects. However, we depart from Booth's (2008) focus on a commercial magazine by exploring how the multiple virtual spaces of roller derby (web images, blogs and social network sites) work to intensify and circulate affects.

\section{Alternative sport and the 'affective turn'}

Sociological work on emotion and affect is a relatively new area of research, drawing mainly from the positivist, constructivist and interactionist perspectives (Thoits, 1989). Most famous is the work of Hochschild who theorized emotion as culturally constructed, proposing ideas such as 'deep' and 'surface' acting (2003). Hochschild (2003) focused on the self 'management' of emotion; how we ensure that we feel the 'right' emotions at the 'right' time within the rule governed context of social life. While contributing a great deal to the sociology of emotion, this body of work has assumed a unified subject as its basis and has largely ignored feminist work on affect. In the area of sport and leisure there have been several notable theoretical approaches to emotion that have heavily influenced the direction of research in the area. For example, Elias and Dunning (2006) have argued that the emergence of a 'civilised' society has prevented people from experiencing and expressing excitement, which they considered vital for 'healthy' human functioning. Sport, and other leisure activities were positioned as enabling the 'repressed euphoria' in society (Elias and Kilminster, 2006). 
In a similar vein Lyng $(1990 ; 2008)$ theorised extreme sports as pushing the boundaries of normality via 'edgework' - the practice of 'working' the 'edges' in high risk sports. The 'edges' being the line between life and death, safety and serious injury, consciousness and unconsciousness: the 'boundary between order and disorder' (Lyng, 2008: 85). Interestingly, edgework skills are regarded as noncognitive and embodied: edgework is a form of embodied reflexivity, as opposed to the cognitive reflexivity proposed by theorists such as Beck (1994) and Giddens (1991). It is this embodied nature that allows 'edge workers' to transcend the structured order of things and transform themselves, if only for a brief moment. Lyng's edgework proposes that one can get outside of culture (Lyng, 2008: 99) via edgework and the experience of 'thrill'. Both Lyng (1990) and Elias and Dunning's (2006) research serves to incorporate an understanding of emotion and affect into sport but with little regard to gender, de-centred subjectivities or mediated culture.

Over the past few years there has been a 'turn to affect' (Blackman and Venn, 2010) across the humanities and social sciences which rejects the unitary subject by privileging multiplicity and becoming, over unity and 'being' (Braidotti, 2011; Deleuze and Guattari, 1987; Probyn, 1996). Sara Ahmed (2004c) uses the terms emotion and affect interchangeably, arguing that they cannot be reduced to psychological states or biological processes. Affect is relational and produced through cultural contexts that shape, and are shaped by, the performance of identity and power differences. She states, 'Emotions shape the very surfaces of bodies, which take shape through the repetition of actions over time' (Ahmed, 2004c: 4). In this sense roller derby, as an embodied and virtual sport culture, is produced through repeated actions that move and shape women's identities in different ways. Extending Ahmed's (2004a) line of thinking we argue that emotions are central to the gendered 
performance of derby identities by and amongst women. Roller derby as an individual pursuit and collective experience enables the "surfacing" of individual and collective bodies through the way in which emotions circulate between bodies and signs' (2004a: 117).

The theorization of affect has only begun to permeate feminist analyses of sport and there is a growing interest from both sociological and critical psychological perspectives (Markula, 2005; Ryba, 2007; Thorpe and Rinehart, 2010). We draw upon this body of work on affect (for example Ahmed, 2004c; Deleuze and Guattari, 1987; Probyn, 1996) to 'read' how selected websites mobilise ideas about becoming roller derby grrrl. By focusing on how the derby body is put into motion, and what affects it generates in relation to other bodies, we offer another way of thinking through the movement of gendered subjectivity as it is imagined, felt and reinvented through virtual sport spaces. Rather than define the roller derby body by its organs and functions, or by its shape and build, 'instead we will seek to count its affects' (Deleuze and Guattari, 1987: 257), by asking, 'what can a roller derby body do?' The women involved in roller derby are not imitating 'being a roller derby grrrl', nor is there such a thing as a 'natural' derby grrrl, an essential set of qualities that define what woman is. Rather, women who play and post images or text are always becoming-derby grrrl as they produce affects (as distinct from static representations of meaning).

Derby grrrls have wide ranging effects, and affects, on each other on the track, blogging and socializing together. Derby bodies can influence debates in feminism, how leagues are managed, injure or care for other players, excite and become excited, participate in music and art, perform fashion and style, and so on. Yet, there has been little analysis of the way feelings move through that virtual space and produce the 
embodied meaning of roller derby. Writing about the movement of affect Kristyn Gorton states that what is important is 'the way in which feeling is negotiated in the public sphere and experienced through the body' (2007: 334).

Within the public sphere roller derby communities can be viewed as a tight knit subcultural group; spectacular, subversive and resistant to dominant modes of behavior (Hall and Jefferson, 1983). Yet this way of conceptualizing roller derby does not account for the range of differences between the women involved. Bennett (1999) argues for a rethinking of the term 'subculture', preferring instead the concept of 'neotribe' for acknowledging how young people's affinities and relations of affect connect them with each other. We also prefer the more fluid concept of neotribe to the more geographical or class based coherence assumed with 'subculture'. In roller derby, ideas about being 'alternative' are normalised, and yet at the same time are continually challenged through differences of age, class, athleticism, sexuality and style. What becomes important is 'an aesthetic form of sociality', rather than any commitment to a particular ideological belief (Sweetman, 2004: 86). As a neotribe, affect plays a particularly important role in the way women in roller derby come to see themselves. Intense affective relationships are played out through different, intersecting, and at times conflicting, neo-tribal identities as derby is configured as a global, growing sport for women.

\section{Derby websites and alternative sport identities: methods and analysis}

Our aim in this article has been to map out the conceptual terrain of affect in order to analyse the role of new media in enabling (and regulating) the affective experience of roller derby. In approaching our analysis of selected websites we did not simply complete a discourse analysis of the way affects are presented in online 
spaces. Rather we explored affects as a way of engaging with, feeling and 'reading' text and images as they moved us (Booth, 2008) to know derby in different ways. Taking our lead from Ahmed, we sought to make visible 'not just the textuality of emotions, but also the emotionality of texts' (2004b: 27). We came to this analysis with different backgrounds to 'feel our way' (Ahmed, 2004c). The first author drew upon her 'insider' experience of roller derby culture (and broader doctoral research) while the second author drew upon her 'outsider' perspective as an observer. Our reading was informed by our interest in the play of gender identities and the tensions that emerged for women in the process of becoming derby grrrls. We focus our analysis on two major themes related to derby culture: sites of empowerment and belonging and the virtual boundaries of the derby body politic.

Our analysis identified four diverse websites: an Australian league's official website (Sun State Roller Girls ${ }^{4}$ ), a UK league's official website (London Roller Girls ${ }^{5}$ ), an online collaborative blog (Live! Derby! Girls! $!^{6}$ ) originating in the US, and a facebook group (Things I've learnt from derby $^{7}$ ) with members from all over the globe. These sites were selected as they evoked some of the ways in which roller derby communities have used virtual spaces to produce and circulate affects. The selection was informed by the first author's immersion in derby cultures over several years and familiarity with the diversity of virtual spaces. Most importantly, they were all 'public' websites that could be accessed by anyone wishing to view their content and without password access. Following the ethical guidelines outlined by the Association of Internet Researchers (Ess and Association of Internet Researchers ethics working group, 2002) we avoided 'lock and key' sites where greater privacy is assumed. No attempts were made to deceive participants on the sites, rather, an 
observational method of 'lurking' was taken -reading without taking part in online discussions or making comments of any sort.

New communication technologies have supported women involved in roller derby to quickly and efficiently communicate with one another, forming virtual and embodied communities spanning most of the developed world. As we demonstrate in our analysis below, it is the movement of different affects that is constantly negotiated by derby communities as they grow and manage the sport. Jodi Dean, writing on affective networks and blogging, insightfully comments on the global context that could be applied to roller derby,

\begin{abstract}
Affective networks produce feelings of community or what we might call 'community without community'...So while relations in affective networks merge and diverge in ways resistant to formalization, the circulation of intensities leaves traces we might mark and follow: blog anxiety, mood flows on Twitter, military message intensification, irrational exuberance (Dean, 2010: 22).
\end{abstract}

\title{
Analysis
}

Derby culture: Sites of empowerment and belonging?

Roller derby league websites commonly articulate the trope of women's 'empowerment' by evoking a collective sense of belonging and the complex pleasure/pain of individual involvement. Yet, the tensions between and among different roller derby leagues highlight the intense affects at play within competitive roller derby communities. There are several 'versions' of roller derby currently vying 
for authority, with each version having slightly different rules and regulations, and, more importantly, a different style $^{8}$. Each version is currently resisting being territorialized, as Deleuze might say, by normative sport frameworks, yet risks splintering and exclusion. The virtual identity of roller derby as a 'singular' sport community is continually undermined through intense conflicts and differences that can be read against each other. In Ahmed's work on affective economies she asks, 'how do emotions work to align some subjects with some others and against other others? How do emotions move between bodies?' (2004a: 117). We extend this line of thinking to consider how affects move between individual and collective derby bodies in virtual space.

Closely modelled on traditional sports, with a strong emphasis on empowerment and fairness, is the Sunstate Roller Girls' website (an Australian league). In the section titled 'About Sunstate Roller Girls' is the following text:

The Sun State Roller Girls (SSRG) are a not-for-profit organisation dedicated to developing and promoting the sport of women's Flat Track Roller Derby in Brisbane by facilitating the development of athletic ability, sportswomanship and goodwill among league members...We promote the empowerment of women in a safe and organised environment that fosters the health, well-being and personal growth of skaters. We honour diversity and encourage selfexpression and are committed to building a network of friendship and support among skaters. We seek continuous improvement in our sport and are committed to democratic principles, constructive dialogue and teamwork. 
Similarly, the London Rollergirls' website is also highly professional. It includes information about upcoming events and a very clear cut section on 'what is roller derby'. In the section titled, 'who are the London Rollergirls?' it states:

We are the London Rollergirls: an all-female, skater-ownedand-run roller derby league based in London, England. Formed in April 2006, we were the first roller derby league established in the UK and are proud to have spearheaded the introduction of this awesome sport to the United Kingdom and Europe. The women that make up the league are not easily defined as there is no prototype for a Rollergirl. You do not need to be tattooed or punk, you do not need to be a sports fanatic but both girls fit in fine and both have a home within the London Rollergirls league. We are comprised of a diverse collection of women of various interests and lifestyles.

The London Rollergirls' mission statement evokes feelings of pride and belonging within a diverse collective that celebrates difference. The website states, 'both [tattooed and highly athletic] girls fit in fine and both have a home within the London Rollergirls league'. The deployment of 'home' is appealing; it draws us into an intimate connection with the organisational body of roller derby where there is no 'normal' femininity. The text on both of these league websites circulates a discourse of 'happy diversity' (Ahmed, 2010) that celebrates women's multiple desires to play, connect, compete and challenge oneself or others. The risky pleasures of derby are framed within the safe comforts of a home for all. At the same time the 'official' sites normalize and reterritorialise derby as a cultural space that becomes known and 
sanctioned in particular ways. Massumi writes of the dangers of this normalizing mirror-vision where a single axis of sight defines identity as static and 'known' (2002: 48). He states,

The single axis of vision stretches you between two surfaces recapitulating the same. On that axis, you resemble yourself perfectly. Stilted, static, a perfect picture. Change is excluded. Change is movement. It is rendered invisible (Massumi, 2002: 48).

Official league sites make visible only the 'empowering' affects (the pleasure of overcoming pain or gendered limits) while the movement of more difficult felt relationships within the sport (frustration, anger or shame) remain unacknowledged. Yet, the unsettling, difficult affects surface within other virtual spaces to disrupt the static official derby narrative of empowerment and belonging.

\section{Virtual boundaries and the derby body politic}

The weblog Live! Derby! Girls! is one site where different views are circulated. The blogs title banner reads, 'Live derby. Girls, girls, girls', along with flashing lights reminiscent of strip clubs and motley crew songs. The blog has 20 contributors, all 'derby girls', all literate and articulate, and very creative. The site embraces the 'derby confession' with stories of overcoming adversity, tales of sexual encounters and many entries about not belonging. The most popular blog entry is entitled, 'Overcoming the dark side of roller derby', and the blogger, TrACDC', opens with the following, 
I'm about to do something taboo... I am about to admit, right here on the interwebs, that roller derby isn't all camaraderie and fishnets (Live Derby Girls, 2011).

In a very diplomatic tone this blogger confesses that the women in roller derby have not always been supportive. She states,

Who do you think it was that gossiped about the demise of my marriage and said extremely unflattering and unforgiving things about me? A derby...Who made me feel like shit about my lack of derby engagement when my life was falling apart and I was sitting at home with a broken hand? A derby. Who made out with my girlfriend after the after party? You better believe it was a derby. Did these experiences effect how I relate to my team and perform on the track? I want to say they didn’t, but they did (Live Derby Girls, 2011).

In response to this blog over 50 comments were posted in the days and weeks following. The responses ranged from impassioned accounts of a destructive 'dark side', shame filled assertions of personal failings, angry claims of exclusion and an out pouring of grief and loss:

I loved derby... I always thought I'd leave with an injury or because I had another path to choose or because I simply stayed long enough. I didn't think I'd leave because I had fallen and shattered into a million pieces. I hope that I can get over it and let it go. Because I don't love derby anymore. And I miss that. 
Derby culture is produced through highly ambivalent emotions where love, passion for the sport and commitment to the imagined community, exists alongside the complex feelings of not belonging. By blogging, posting and producing content for websites, the women involved mark out their entitlement to belong in different ways. To speak out against roller derby, or to express negative affects (of 'not love', or hate), is to be positioned as 'other' within the public sphere. This otherness evokes displeasures that are defined against the pleasures of becoming roller derby grrrl that Ahmed (2004c) argues signifies one's 'entitlement' to belong. The virtual space of derby culture is claimed through enjoyment that is 'witnessed' by others (Ahmed, 2004c). Those who show the most enjoyment, the most pleasure - those who love roller derby the most - are the most entitled. Against the claims of 'happy diversity' within the vision statements of major leagues, exist sites produced by disaffected players who make visible the complex affective economies that are intertwined with the power relations of women's sport.

Extending Probyn's (2005: 85) argument about television as a key cultural site where emotion is produced, we view new communication technologies as another more complex interactive and 'felt' space. In particular, facebook is an important contemporary site where individual and collective identities are produced and negotiated (boyd and Ellison, 2007). 'Things I learned from roller derby' is a public facebook group with over 4,500 fans and is a space where anyone can contribute to an ongoing discussion of roller derby. Daily comments are made on this facebook page and it provides a good example of how social network sites circulate, and in the case or roller derby, intensify affects through stories of pleasure and pain. In this context pride, anger and passion are validated, while sadness and shame are not (Carlson, 2010; Finley, 2010). On both the facebook site (Things I learned from roller derby) 
and the blog (Live!Derby!Girls!) described earlier, 'Shut up and skate' is a common response given to any expression of 'girly' emotion such as sadness or hurt.

Interactive websites create a collective space where different derby identities are enacted via the rules and gender norms that regulate this 'alternative' sport via the affective power relations that include/exclude. Comments on the blog act as a 'skin', a shifting boundary regulating who is 'in' and who is 'out' of the roller derby body politic; an online participant is 'pounced on' by others for saying something against the status quo. Anyone who expresses too much 'hurt' is 'out'. Women who demonstrate they have a thick skin, who can handle pain (and derive pleasure from pushing and working on the body) are 'in'. A recent comment by the administrators of the group stated: 'there is no entitlement to anything. There is only earning'. Over 80 people 'liked' this post and five women commented, expressing an emotional response to this highly charged issue - enthusiasm, sorrow, and anger. Text and images evoke the subjection of the individual derby body through sport practices that involve pain, pushing oneself beyond gendered limits and intense competition. Moreover, derby websites enable, and also regulate, the flow of meaning for individuals through the discursive boundaries (or skin) of the collective roller derby 'body politic' (Gatens, 1996).

Yet, derby is an imagined community that is profoundly fractured, and fractious, because of the complex range of affects that are evoked in the desire to identify an alternative space of belonging. Websites that mobilise and make visible the 'difficult affects' of anger, shame or loss, provide examples of 'when emotions work against us or are used against us' (Gorton, 2007: 345). The interactive digital interface demonstrates the productive working of power through affective relationships within the virtual space of derby culture. Websites operate through a 
different register of meaning, one that does not simply 'represent' a women's sport culture, but is as intense as the sport experience itself. By writing about, in and through the dark side of derby culture, women's marginalized voices work to 'trouble' the truth claims of empowerment and inclusion of diverse identities on the official league websites.

\section{Conclusion}

In this article we have explored another way of thinking through the embodied and virtual movement of affect in roller derby as an 'alternative' women's sport culture. Roller derby culture incites women to participate through an ongoing negotiation of the individual and collective identity of sport that is at once real and virtual, about art and active embodiment, and troubles an easy identification with masculine or feminine norms. The process of becoming a roller derby grrrl is importantly shaped by meaning produced through cultural artefacts in virtual spaces beyond the track - the blogs, league sites, facebook commentary and other aspects of mediated sport culture. The representation of derby is never static as meaning is constituted through the movement of writing, reading and visualizing the experience of individual and collective play. Comments posted online circulate between websites, images are uploaded and downloaded, passions and desires are shared, pain and injury is celebrated. Our analysis has identified the significance of this virtual production and reinvention of roller derby culture/s. Multiple roller derby identities are contested and made 'real' via virtual space. We have argued that these individual and collective identities are produced through the dynamic relations of affect that are intertwined with the exercise of power - the power to include or exclude despite the claims that derby is an 'empowering' sport for women. 
The 'real' and the 'virtual' are commonly held in opposition to one another, however in roller derby it is impossible to draw a solid line between these aspects of sport culture. The intensity of affect experienced by derby players is made visible and 'real' within the public sphere via the images and text posted online. These affects are used to mark out the boundaries of community - women share with each other the pleasure and importantly the physical and emotional pain of roller derby. However, the representation of roller derby through a discourse of empowerment can render invisible the complexity and diversity of women's affective experiences. Roller derby grrrls are not static subjects as they actively make use of different virtual spaces to create different ways of seeing, feeling and exploring identity. Acknowledging the multiplicity of desires within roller derby is akin to what Massumi names movementvision (2002: 50). Massumi argues, that 'to see oneself standing as others see one is not the same as seeing oneself walking as others see one' (2002: 50). Through the creation of virtual cultural artefacts women in roller derby make visible the movement of affect through which they transform themselves from freshmeat ${ }^{10}$, to the team, onto the track and beyond in an ongoing process of becoming. The becoming bodies in roller derby are produced through affective relationships that shape individual identities that are also experienced as organisational and corporeal. As a sport 'run for and by women' our analysis of derby reveals the complex working of power through affective relationships that 'trouble' normative claims about empowerment.

As a women's only sport there is pleasure in taking up the gender troubling identity of 'derby grrrl', 'freshmeat' or 'blocker/jammer'. Through roller derby women can challenge sexist assumptions or feelings of marginalisation within the social. They can take up subject positions that offer an alternative to conventional gender scripts which emphasise responsibility for others (mothering), demure 
niceness or even work centered ambition. Yet, becoming roller derby grrrl involves negotiating a number of 'alternative' scripts and normative assumptions about what it means to embody a different kind of gender identity. In this sense, derby culture is also the site of reterritorialisation where gender norms are reinscribed through the value accorded to working through pain and deriving pleasure from overcoming 'feminised' emotions. Yet, the meaning of roller derby for women cannot be easily categorized or territorialized by one set of sport norms or rules. Even its position as a woman's only sport is challenged by some, with men starting up leagues of their own and some leagues having both male and female teams ${ }^{11}$. Instead, the shape of derby is continually marked out through the flow of affects, of pain, frustration, passion, desire, and love, which connects and separates individual and collective bodies. To enable these flows, women in roller derby mobilise virtual spaces and digital technologies, as a defining aspect of a creative sport culture. Drawing on the work of feminists such as Probyn and Ahmed, we have explored how 'emotions do things, and work to align individuals with collectives - or bodily space with social space through the very intensity of their attachments' (Ahmed, 2004b: original italics). The intensity of women's attachment to roller derby is made clear through the emotionality of texts (such as the Live! Derby! Girls! blog described above) and the contradictory desires articulated in online communities.

In our analysis we have identified how digital communication technologies have enabled the formation of diverse roller derby communities. Yet, these communities are tenuous; they are always in motion, which is also part of the attraction for many of the women involved. With the proportion of women participating in organized sport decreasing (Australian Bureau of Statistics, 2011; Bailey, Wellard and Dismore, 2004), roller derby is an interesting counter example of 
a sport that is able to attract thousands of participants worldwide. Roller derby leaves a strong 'impression' on everyone who comes in contact with it. Whether they are disgusted, excited, inspired, or scared, derby has an effect and affect. Yet, within websites and online discussions roller derby is contested and identities are policed and regulated in ways that undermine discourses of empowerment and belonging.

By considering how the mediated affects of pleasure, pain, and belonging are crucial to sport cultures, we have argued for the consideration of affect, as influenced by feminisim, cultural studies and geography. We reiterate Markula's concern with developing feminist analyses that 'leave behind the examination of the static, visible representations of the body to engage with visceral, ephemeral movement to create a line of flight to new territories of feminist research' (2006: 43). In this sense we argue that privileging flows of movement and different registers of meaning enables a better understanding of how pleasures and pains are embodied by women in the formation of 'new' sports. Paying attention to the movements of affect can open up new ways of approaching questions about power and change within existing and new sport cultures.

\section{Notes}

${ }^{1}$ The use of 'Grrrl' is a 'feminist reclamation of the word girl with a less polite and more assertive political stance' Rosenberg, J \& Garofalo, G (1998) Riot grrrl: Revolutions from within. Signs, 23: 809-841.

2 See the International Roller Girls' Master Roster, www.twoevils.com for a list of all players and leagues around the world. Currently there are over 34,735 players registered worldwide (at March, 2012).

${ }^{3}$ Men play mostly supportive roles as referees and coaches, although a small number of male teams are starting to promote themselves

4 http://sunstaterollergirls.com/

5 http://www.londonrollergirls.com/

${ }^{6} \mathrm{http}: / /$ livederbygirls.com/

${ }^{7}$ http://www.facebook.com/pages/Things-I-learned-from-Derby/349318613615

8 Two of the main leagues that are vying for authority within the roller derby community are the Women's Flat Track Derby Association http://wftda.com/ and Modern Athletic Derby Endeavour http://www.skatemade.org/. These leagues have slightly different rules, and different values and ways of organising competition. 
${ }^{9}$ Women in roller derby take on a 'derby name' or moniker for themselves. A list of registered names around the world can be found on the international list,

http://www.twoevils.org/rollergirls/

${ }_{10}$ Women new to roller derby are known as 'freshmeat'

${ }^{11}$ For example, Brisbane City Rollers, www.brisbanecityrollers.com/ 


\section{References}

(2008) Western Regionals - almost as good as being there. roller derby blog [Online]. Available from: http://www.rollerderbyblog.com/ [Accessed 01/10/2011].

(n.d.) International Roller Girls Master Roster [Online]. Available: http://www.twoevils.org/rollergirls/ [Accessed].

Ahmed, S (2004a) Affective economies. Social Text, 22: 117.

Ahmed, S (2004b) Collective feelings. Theory, Culture \& Society, 21: 25.

Ahmed, S (2004c) The cultural politics of emotion. Edinburgh: Edinburgh University Press.

Ahmed, S (2010) Feminist killjoys (and other willful subjects). The scholar and feminist online, 8.

Australian Bureau of Statistics (2006) National Centre for Culture and Recreation Statistics: Women's Participation in Sport and Physical Activities [Online]. Available:

http://www.ausport.gov.au/ data/assets/pdf file/0007/276937/ABSwomens participation sport physical activity.pdf [Accessed viewed 18 June 2010].

Australian Bureau of Statistics (2011) Sport and Physical Recreation: A Statistical Overview, Australia [Online]. Available:

http://www.abs.gov.au/ausstats/abs@.nsf/Latestproducts/4156.0Main \%20Features12011?opendocument\&tabname=Summary\&prodno=4156. 0\&issue $=2011 \&$ num $=\&$ view $=$ [Accessed viewed 18 April 2011].

Bailey, R, Wellard, I \& Dismore, H 2004. Girls participation in physical activities and sports: benefits, patterns, influences and ways forward. In: Education, ICfSSaP (ed.). Germany: Canterbury Church University College, UK.

Beaver, TD (2012) "By the Skaters, for the Skaters" The DIY Ethos of the Roller Derby Revival. Journal of Sport \& Social Issues.

Beck, U, Giddens, A \& Lash, S (1994) Reflexive modernization: politics, tradition and aesthetics in the modern social order. California: Stanford Univ Pr.

Bennett, A (1999) Subcultures or neo-tribes? Rethinking the relationship between youth, style and musical taste. Sociology, 33: 599.

Blackman, L \& Venn, C (2010) Affect. Body \& Society, 16: 7.

Booth, D (2008) (Re)reading the Surfers' Bible: the affect of Tracks. Continuum, 22: 17-35.

boyd, d \& Ellison, N (2007) Social Network Sites: Definition, History, and Scholarship. Journal of Computer-Mediated Communication, 13: 210-230.

Braidotti, R (2011) Nomadic Subjects. New York: Columbia University Press.

Carlson, J (2010) The female significant in all-women's amateur roller derby. Sociology of Sport Journal, 27: 428-440.

Carlson, J (2011) Subjects of stalled revolution: A theoretical consideration of contemporary American femininity. Feminist Theory, 12: 75.

Castells, M (2003) The Internet galaxy: Reflections on the Internet, business, and society. Oxford: Oxford University Press.

Cohen, JH (2008) Sporting-self or Selling Sex: All-Girl Roller Derby in the 21st Century. Women in Sport and Physical Activity Journal, 17: 24-33.

Dart, JJ (2009) Blogging the 2006 FIFA world cup finals. Sociology of Sport Journal, 26: 107-126. 
Dean, J (2010) Affective Networks. MediaTropes, 2: 19-44.

Deleuze, G \& Guattari, F (1987) A thousand plateaus: Capitalism and schizophrenia. Minneapolis: University of Minnesota Press.

Donnelly, MK. (2012) The production of women onlyness: Women's flat track roller derby and women-only home improvement workshops. McMaster University

Driscoll, C (1999) Girl Culture, Revenge and Global Capitalism: Cybergirls, Riot Grrls, Spice Girls. Australian Feminist Studies, 14: 173-193.

Dunning, E \& Maguire, J (1996) Process-Sociological Notes on Sport, Gender Relations and Violence Control. International Review for the Sociology of Sport, 31: 295-319.

Elias, N \& Kilminster, R (2006) The Collected Works of Norbert Elias. Dublin: University College Dublin Press.

Ess, C \& Association of Internet Researchers ethics working group (2002) Ethical decision-making and Internet research: recommentations from aoir ethics working committee [Online]. AoiR. Available: www.aoir.org/reports/ethics.pdf [Accessed 1st March 2012].

Finley, NJ (2010) Skating Femininity: Gender Maneuvering in Women's Roller Derby. Journal of Contemporary Ethnography, 39: 359 - 387.

Garrison, EK (2000) U.S. feminism-grrrl style! Youth (sub)cultures and the technologics of the third wave. Feminist Studies, 26: 141-170.

Gatens, M (1996) Imaginary bodies: Ethics, power and corporeality. London: Routledge.

Gibbs, A (2001) Contagious feelings: Pauline Hanson and the epidemiology of affect. Australian Humanities Review, 24.

Gibson, C (1999) Subversive sites: rave culture, spatial politics and the internet in Sydney, Australia. Area, 31: 19-33.

Giddens, A (1991) Modernity and self-identity: Self and society in the late modern age. Cambridge: Polity Press.

Gorton, K (2007) Theorizing emotion and affect. Feminist Theory, 8: 333.

Gregg, MC (2006) Cultural Studies' Affective Voices. Houndmills: Palgrave Macmillan.

Hall, S \& Jefferson, T (eds.) (1983) Resistance through rituals: Youth subcultures in post-war Britain, London: Hutchinson \& co.

Hargreaves, JA (1990) Gender on the sports agenda. International Review for the Sociology of Sport, 25: 287.

Harris, A (2003) gURL scenes and grrrl zines: the regulation and resistance of girls in late modernity. Feminist review, 75: 38-56.

Hochschild, AR (2003) The managed heart. Berkeley: University of California Press

Hodkinson, P (2003) Net. Goth: Internet Communication and (Sub) Cultural Boundaries. The post-subcultures reader: 285-298.

Joulwan, M (2007) Roller girl, totally true tales from the track. New York: Simon and Schuster.

Kahn, R \& Kellner, D (2003) Internet subcultures and oppositional politics. In: Muggleton, D \& Weinzierl, R (eds.) The post-subcultures reader. Oxford: Berg.

Kahn, R \& Kellner, D (2004) New media and Internet activism: From the battle of Seattle to blogging. New Media \& Society, 6: 87-95. 
Kearney, MC (2011) Tough Girls in a Rough Game. Feminist Media Studies, 11: 283-301.

Leonard, DJ (2009) New media and global sporting cultures: Moving beyond the clichés and binaries. Sociology of Sport Journal, 26: 1-16.

Live Derby Girls (2011) Overcoming the dark side of roller derby [Online]. Available: http://livederbygirls.com/2011/02/13/overcoming-the-darkside-of-roller-derby/ [Accessed 12/06/11].

Luckman, S (1999) (En) gendering the digital body: feminism and the Internet. Hecate, 25: 36-47.

Lumby, C, Caple, H \& Greenwood, K 2009. Towards a level playing field: sport and gender in Australian media. In: Australian Sports Commission (ed.).

Lyng, S (1990) Edgework: A social psychological analysis of voluntary risk taking. American Journal of Sociology, 95: 851-886.

Lyng, S (2008) Risk-taking in sport: edgework and reflexive community. In: Atkinson, M \& Young, K (eds.) Tribal play. Subcultural journeys through sport. Bingley: Emerald Group Publishing Limited.

Mabe, C (2008) Roller derby. The history and all-girl revival of the greatest sport on wheels. Denver: Speck Press.

MacKay, S \& Dallaire, C (2012) Skirtboarder net-a-narratives: Young women creating their own skateboarding (re)presentations. International Review for the Sociology of Sport.

Manovich, L (2009) The Practice of Everyday (Media) Life: From Mass Consumption to Mass Cultural Production? Critical Inquiry, 35: 319-331.

Markula, P (ed.) (2005) Feminist Sport Studies: Sharing Experiences of Joy and Pain, New York: State University of New York Press.

Markula, P (2006) Deleuze and the Body Without Organs. Journal of Sport \& Social Issues, 30: 29-44.

Massumi, B (2002) Parables for the virtual. Durham: Duke University Press.

Oates, TP (2009) New media and the repackaging of NFL fandom. Sociology of Sport Journal, 26: 31-49.

Pavlidis, A (2011) From Riot Grrrls to roller derby? Exploring the relations between gender, music and sport. Leisure Studies: 1-12.

Peluso, N. (2011) High heels and fast wheels: alternative femininities in neoburlesque and flat-track roller derby. Ph.D University of Connecticut.

Probyn, E (1996) Outside belongings. London: Routledge.

Probyn, E (2005) Blush. Sydney: University of New South Wales Press.

Rosenberg, J \& Garofalo, G (1998) Riot grrrl: Revolutions from within. Signs, 23: 809-841.

Ruddock, A, Hutchins, B \& Rowe, D (2010) Contradictions in media sport culture: The reinscription of football supporter traditions through online media. European Journal of Cultural Studies, 13: 323.

Ryba, TV (2007) Cartwheels on Ice: A Phenomenological Exploration of Children's Enjoyment in Competitive Figure Skating. The Online Journal of Sport Psychology, 9: 58-73.

Storms, CE (2010) There's no sorry in roller derby: A feminist examination of the collective identity formation of women in the full contact sport of roller derby. New York Sociologist, 3: 68 - 87.

Sweetman, P (2004) Tourists and travellers?'Subcultures', reflexive identities and neo-tribal sociality. In: Bennett, A \& Kahn-Harris, K (eds.) After 
subculture, critical studies in contemporary youth culture. Hampshire: Palgrave.

Thoits, PA (1989) The sociology of emotions. Annual Review of Sociology, 15: 317-342.

Thorpe, H (2008) Foucault, technologies of self, and the media. Discourses of femininity in snowboarding culture. Journal of Sport \& Social Issues, 32: 199-229.

Thorpe, H \& Rinehart, R (2010) Alternative sport and affect: nonrepresentational theory examined. Sport in Society, 13: 1268-1291.

Wearing, B (1998) Leisure and feminist theory. London: Sage Publications Ltd.

Williams, JP (2003) The straightedge subculture on the Internet: A case study of style-display online. Media International Australia Incorporating Culture and Policy, 107: 61-74.

Wilson, B (2008) Believe the Hype? The Impact of the Internet on Sport-Related Subcultures. In: Atkinson, M \& Young, K (eds.) Tribal play: subcultural journeys through sport. Emerald Group Pub Ltd. 